\title{
PENGEMBANGAN SISTEM MANAJEMEN DATABASE DAN PENGAMBILAN KEPUTUSAN KRITERIA PENDUDUK MISKIN KABUPATEN KUTAI KARTANEGARA PROVINSI KALIMANTAN TIMUR
}

\author{
Ummul Hairah \\ ummihairah@gmail.com \\ Program Studi Teknik Informatika Universitas Mulawarman
}

\begin{abstract}
Abstrak
Masalah terpenting dalam penanggulangan kemiskinan adalah bagaimana mendapatkan data kemiskinan yang ideal sementara di satu sisi terdapat beberapa versi kriteria kemiskinan yang dikeluarkan oleh beberapa stakeholder. Untuk itu perlu dirancang suatu sistem manajemen data yang mengintegrasikan beberapa kriteria kemiskinan berbeda tersebut agar dapat menghasilkan data keluarga miskin yang ideal menjadi target program penanggulangan kemiskinan di kabupaten Kutai Kartanegara Kalimantan Timur. Penelitian ini menghasilkan sebuah sistem berbasis website yang dapat digunakan oleh admin untuk melakukan pengelolaan data stakeholder dan kriteria kemiskinan yang ditetapkan, program bantuan penanggulangan kemiskinan, dan data calon penerima bantuan. Selain itu masyarakat umum maupun pihak lain yang membutuhkan juga dapat melihat informasi mengenai kriteria, program bantuan dan data penerima bantuan. Hasil penelitian menunjukkan bahwa dengan adanya system ini, proses pengambilan keptusan warga penerima program bantuan kemiskinan menjadi mudah dan akurat. Semakin banyak indikator yang dimasukkan dalam kriteria program bantuan data keluarga miskin yang dihasilkan akan lebih ideal.
\end{abstract}

Kata kunci: pengambilan, keputusan, integrasi, kemiskinan, kriteria.

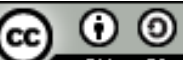

EY SA ILKOM Jurnal IImiah work is licensed under a CCA-SA 4.0 International License.

\section{Pendahuluan}

Masalah kemiskinan merupakan salah satu persoalan mendasar yang menjadi pusat perhatian pemerintah di negara manapun, terutama di negara berkembang. Kemiskinan didefinisikan sebagai suatu kondisi dimana seseorang tidak bisa memenuhi kebutuhan dasar hidup mereka baik dari aspek pangan maupun non pangan. Seseorang akan dikatakan miskin jika mereka berada di bawah garis kemiskinan (BPS, 2015).

Salah satu aspek penting untuk mendukung Strategi penanggulangan kemiskinan adalah tersedianya data kemiskinan yang akurat dan tepat sasaran. Pengukuran kemiskinan yang dapat dipercaya dapat menjadi instrumen tangguh bagi pengambil kebijakan dalam memfokuskan perhatian pada kondisi hidup orang miskin.

Untuk mengukur kemiskinan, variabel yang digunakan BPS dalam menentukan ukuran kemiskinan sebanyak 14 variabel, seperti: kondisi perumahan, kemampuan daya beli, pendidikan, pekerjaan serta aset rumah tangga/keluarga. Sementara BKKBN menetapkan kategori miskin adalah keluarga yang masuk ke dalam tahap Keluarga Pra Sejahtera (Pra-KS) dan Keluarga Sejahtera I (KS I), yang dilihat dari beberapa kriteria seperti seluruh anggota keluarga tidak mampu makan dua kali sehari, seluruh anggota keluarga tidak memiliki pakaian berbeda untuk di rumah, bekerja/sekolah, dan bepergian, bagian terluas dari rumahnya berlantai tanah, dan tidak mampu membawa anggota keluarga ke sarana kesehatan.

Kabupaten Kutai Kartanegara sebagai salah satu kabupaten di Provinsi Kalimantan Timur memiliki sebuah program bantuan bagi warganya yang termasuk dalam kategori tidak mampu. Dalam menentukan warga tidak mampu, Kabupaten Kutai Kartanegara menetapkan kriteria tersendiri bagi warganya. Hal ini menjadi masalah tersendiri karena tidak jelas masyarakat miskin yang mana yang harusnya ideal atau tepat menjadi target program penanggulangan kemiskinan. Untuk itu perlu dilakukan penyesuaian kriteria miskin agar penentuan keluarga miskin tidak salah sasaran. Oleh karena itu diperlukan adanya langkah-langkah strategis untuk mendapatkan data kriteria kemiskinan yang terintegrasi dalam sebuah sistem bank data kriteria karena berbagai versi yang dikeluarkan menurut instansi atau institusi yang berbeda-beda tersebut. 


\section{LandasanTeori}

\subsection{Integrasi data}

Integrasi data merupakan proses mengkombinasikan dua atau lebih set data agar mempermudah dalam berbagi dan analisis, dalam rangka mendukung manajemen informasi di dalam sebuah lingkungan kerja. Integrasi data menggabungkan data dari berbagai sumber database yang berbeda. Syarat integrasi data dapat dipenuhi dengan berbagai cara seperti konsisten dalam penamaan variabel, konsisten dalam ukuran variabel, konsisten dalam struktur pengkodean dan konsisten dalam atribut fisik dari data. Masalah-masalah yang ada pada integrasi data yaitu heterogenitas (keanekaragaman) data, otonomi sumber data, kebenaran dan kinerja query/permintaan [4].

\subsection{Kemiskinan}

Secara harfiah, miskin itu berarti tidak berharta benda [6]. Miskin juga berarti tidak mampu mengimbangi tingkat kebutuhan hidup standard dan tingkat penghasilan dan ekonominya rendah. Secara singkat kemiskinan dapat didefenisikan sebagai suatu standar tingkat hidup yang rendah yaitu adanya kekurangan materi pada sejumlah atau segolongan orang dibandingkan dengan standard kehidupan yang berlaku dalam masyarakat yang bersangkutan [5].

Istilah Kemiskinan selalu melekat dan begitu populer dalam masyarakat yang sedang berkembang. Istilah itu sangat mudah diucapkan tetapi begitu mudah untuk menentukan yang miskin itu yang bagaimana siapa yang tergolong penduduk miskin. Dalam menetapkan kriteria rakyat miskin, terdapat 14 variabel yang digunakan oleh BPS. Variabel tersebut adalah :

1) Luas lantai bangunan tempat tinggal kurang dari $8 \mathrm{~m} 2$ per orang.

2) Jenis lantai tempat tinggal terbuat dari tanah/bambu/kayu murahan.

3) Jenis dinding tempat tinggal dari bambu/ rumbia/ kayu berkualitas rendah/tembok tanpa diplester.

4) Tidak memiliki fasilitas buang air besar/ bersama-sama dengan rumah tangga lain.

5) Sumber penerangan rumah tangga tidak menggunakan listrik.

6) Sumber air minum berasal dari sumur/ mata air tidak terlindung/ sungai/ air hujan.

7) Bahan bakar untuk memasak sehari-hari adalah kayu bakar/ arang/minyak tanah.

8) Hanya mengkonsumsi daging/ susu/ ayam dalam satu kali seminggu.

9) Hanya membeli satu stel pakaian baru dalam setahun.

10) Hanya sanggup makan sebanyak satu/ dua kali dalam sehari.

11) Tidak sanggup membayar biaya pengobatan di puskesmas/ poliklinik.

12) Sumber penghasilan kepala rumah tangga adalah: petani dengan luas lahan $500 \mathrm{~m} 2$, buruh tani, nelayan, buruh bangunan, buruh perkebunan dan atau pekerjaan lainnya dengan pendapatan dibawah Rp. 600.000,- per bulan.

13) Pendidikan tertinggi kepala rumah tangga: tidak sekolah/ tidak tamat SD/ tamat SD.

14) Tidak memiliki tabungan/ barang yang mudah dijual dengan minimal Rp. 500.000,- seperti sepeda motor kredit/ non kredit, emas, ternak, kapal motor, atau barang modal lainnya.

Jika minimal 9 dari 14 variabel tersebut terpenuhi, maka suatu rumah tangga sudah dikategorikan miskin [2].

Sedangkan kriteria kemiskinan menurut BKKBN adalah mereka yang termasuk dalam kategori prasejahtera dan sejahtera I. Dalam Program Pembangunan Keluarga Sejahtera BKKBN, Keluarga Pra Sejahtera dan Keluarga Sejahtera I lebih tepat disebut sebagai Keluarga Tertinggal. Karena yang disebut sebagai Keluarga Pra Sejahtera adalah keluarga yang belum dapat memenuhi kebutuhan dasarnya, memenuhi kebutuhan makan minimal dua kali sehari, pakaian yang berbeda untuk di rumah, bekerja, sekolah, dan bepergian, memiliki rumah yang bagian lantainya bukan dari tanah, dan belum mampu untuk berobat di sarana kesehatan modern. Keluarga Sejahtera I adalah keluarga yang kondisi ekonominya baru bisa memenuhi kebutuhan dasarnya secara minimal, tetapi belum mampu memenuhi kebutuhan sosial psikologisnya [3].

Berbeda dengan kriteria dari BPS dan BKKBN, Kabupaten Kutai Kartanegara menetapkan kriteria tersendiri bagi warga tidak mampu yang akan menerima program bantuan yang terdiri dari:

1) Janda Tua yang meliputi :

a) Wanita yang bercerai dari suaminya dan berusia diatas 50 (lima puluh) tahun.

b) Berstatus sebagai kepala rumah tangga dan pencari nafkah.

c) Tidak memiliki penghasilan tetap yang dapat memenuhi kebutuhan pokok keluarga.

d) Tidak ada keluarga yang membantu pemenuhan kebutuhan hidupnya.

e) Memiliki keluarga/anak tetapi termasuk dalam kategori penduduk miskin.

f) Berdomisili secara terus menerus di wilayah Kabupaten Kutai Kartanegara minimal selama 2 (dua) tahun.

2) Lanjut Usia yang meliputi :

a) Pria atau wanita.

b) Berstatus cerai atau masih menikah, dipilih salah satu dari pasangan suami istri. 
c) Berusia diatas 60 (enam puluh) tahun.

d) Tidak memiliki penghasilan tetap yang dapat memenuhi kebutuhan pokoknya.

e) Tidak ada keluarga yang membantu.

f) Mempunyai kelaurga/anak tetapi termasuk dalam kategori penduduk miskin.

g) Berdomisili secara terus menerus di wilayah Kabupaten Kutai Kartanegara minimal selama 2 (dua) tahun.

3) Anak Yatim yang meliputi :

a) Pria atau wanita.

b) Berusia maksimal 18 (delapan belas) tahun dan belum menikah.

c) Termasuk dalam kategori penduduk miskin.

d) Tidak ada keluarga atau orang lain yang mengurus.

e) Tidak memiliki sumber penghasilan yang dapat memenuhi kebutuhan hidupnya.

f) Tidak mendapatkan pelayanan dan pembinaan dan Panti Asuhan.

g) Maksimal dalam satu keluarga terdapat 2 (dua) orang anak yatim piatu.

h) Berdomisili di wilayah Kabupaten Kutai Kartanegara secara terus menerus minimal selama 2 (dua) tahun.

4) Penyandang Cacat yang meliputi :

a) Pria atau wanita.

b) Mengalami cacat fisik dan atau mental, sehingga tidak dapat melaksanakan aktifitas sehari hari secara normal.

c) Tidak Dapat bekerja sehingga tidak memiliki penghasilan yang dapat memenuhi kebutuhan hidupnya.

d) Tidak mendapatkan pelayanan dan pembinaan dari Panti Sosial atau Yayasan Sosial.

e) Berdomisili secara terus menerus di wilayah Kabupaten Kutai Kartanegara minimal selama 2 (dua) tahun [1].

\section{Metode}

Pengembangan sistem manajemen database dan pengambilan keputusan kriteria penduduk miskin Kabupaten Kutai Kertanegara Ini menggunakan model proses waterfall (linear sekuensial). Tahapannya dimulai dari tahap perencanaan, analisis kebutuhan, perancangan, implementasi dan perawatan secara berurutan.

a. Context Diagram

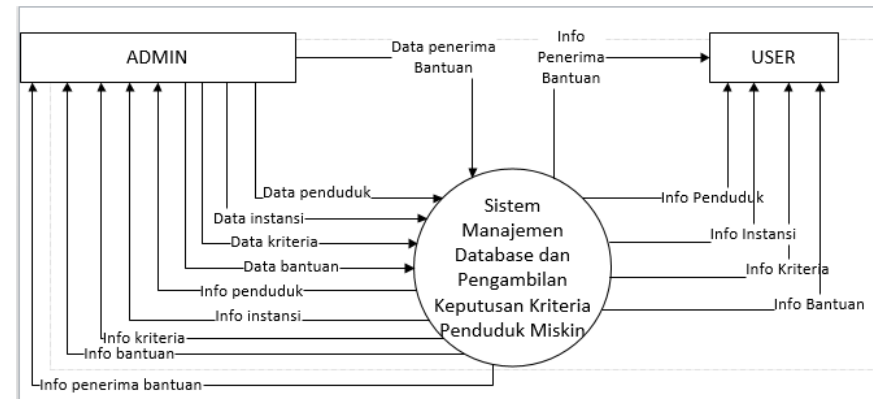

Gambar 1. Context Diagram

b. Data Flow Diagram

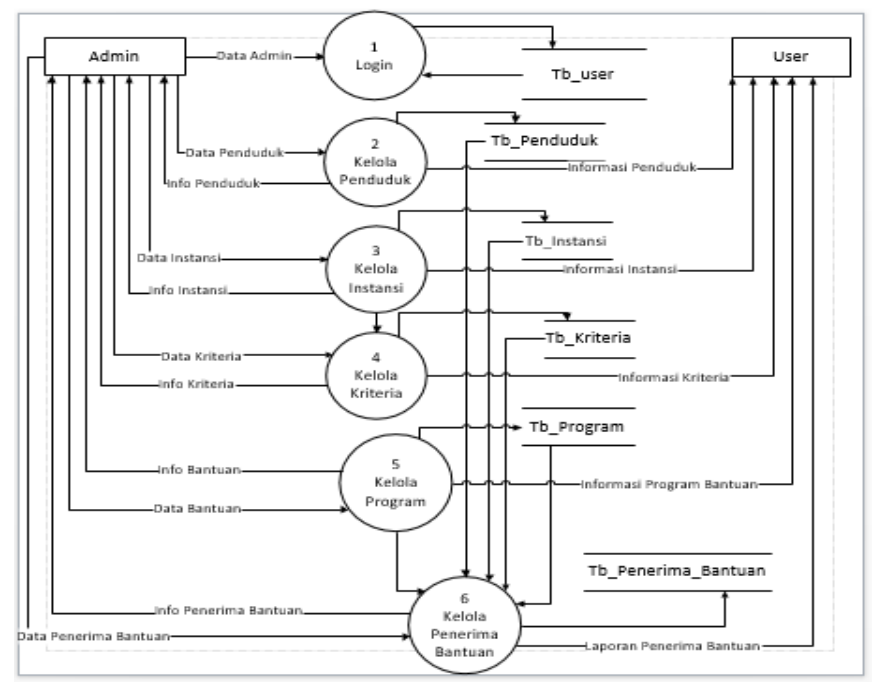

Gambar 2. Data Flow Diagram Level 0. 
c. Entity Relationship Diagram

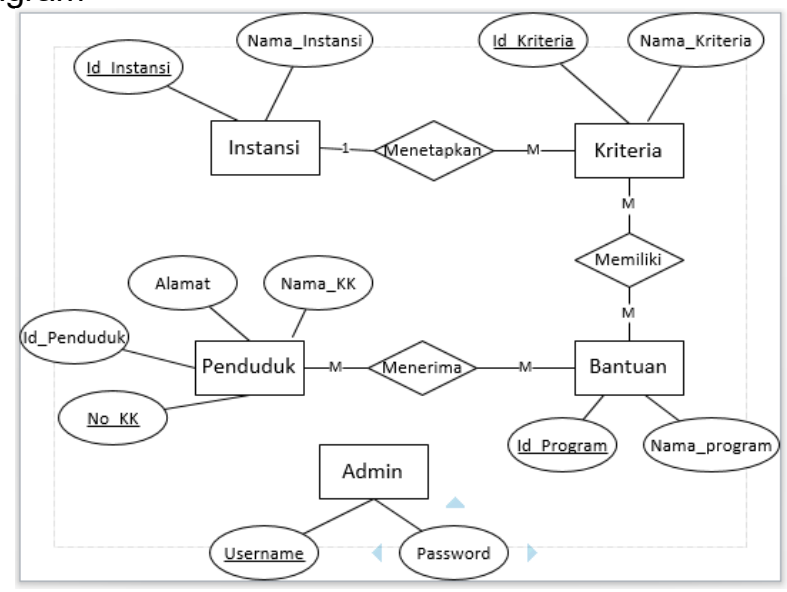

Gambar 3. Entity Relationship Diagram

\section{d. Teknik Pengujian Sistem}

Metode pengujian yang digunakan dalam penelitian ini adalah metode black box untuk menguji apakah fungsionalitas sistem telah berjalan sesuai dengan fungsinya. Dan analisis hasil akan diuji menggunakan metode verifikasi dan validasi (V\&V).

\section{Hasil}

\subsection{Implementasi}

Sistem manajemen database dan pengambilan keputusan kriteria penduduk miskin ini dapat digunakan oleh pengguna yang terbagi atas 2 level otoritas yaitu :

a. Level User

Level user adalah semua pengguna dapat mengakses sistem ini tanpa harus login. User dapat mengakses berbagai informasi dari menu profil tentang objek penelitian, menu kriteria instansi, menu program bantuan pengentasan kemiskinan, menu laporan penerima bantuan dan menu profil peneliti.

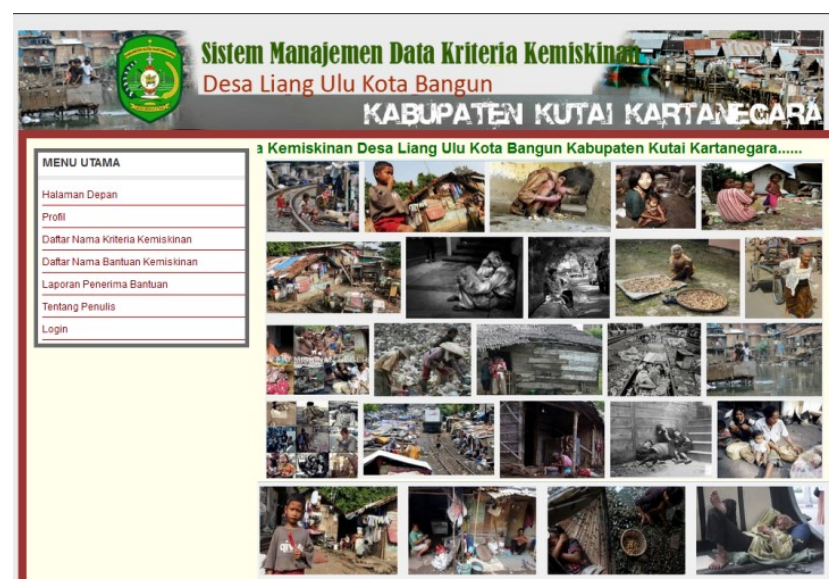

Gambar 4. Halaman Utama Pengguna

b. Level Administrator

Level administrator dalam sistem manajemen database kriteria kemiskinan ini adalah pengguna yang dapat mengelola data, yaitu pihak aparatur desa yang telah dipilih. Untuk mengakses ke dalam system, admin harus melalui proses otentifikasi pada menu login. 


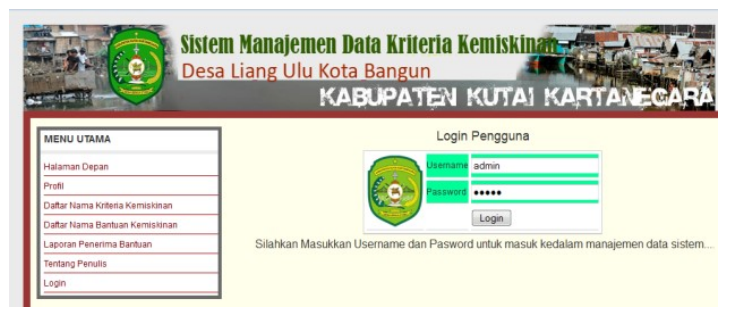

Gambar 5. Menu Login Admin

Menu admin terdiri dari beberapa modul, sebagai berikut:

1) Modul data master, merupakan data dasar atau data primer dalam penelitian ini yaitu :

a) Master data penduduk

Menu penduduk ini menampilkan data penduduk yang telah dimasukkan oleh seperti ditunjukkan pada gambar 6. Data penduduk dapat diubah ataupun dihapus melalui pilihan menu aksi.

\section{KADUPATEN KUA KATANBQA}

Data Penduduk

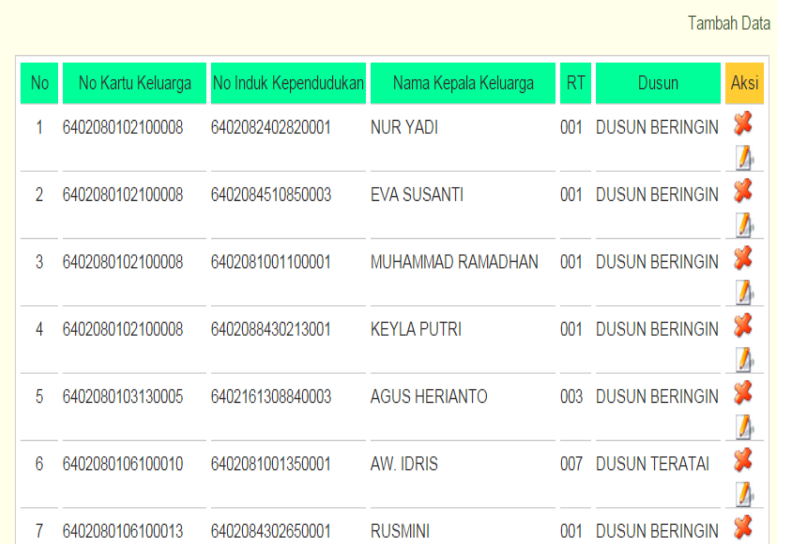

Gambar 6. Halaman Master Data Penduduk

b) Master data instansi

Menu instansi ini menampilkan master data instansi yang menetapkan kriteria. Data pada master data instansi ini dapat ditambah, diubah ataupun dihapus.

\section{KABVATEN KUAA KATANBGA}

Data Instansi

\begin{tabular}{|c|c|c|c|}
\hline Kode & Nama Instansi & Keterangan & Aksi \\
\hline 001 & BKKBN & Badan Kordinasi Keluarga Berencana Nasional & $8 D$ \\
\hline 002 & BPS & Badan Pusat Statistik & $\$ \Delta$ \\
\hline 003 & Kutai Kartanegara & Pemerintah Daerah Kabupaten Kutai & $8 D$ \\
\hline
\end{tabular}

Gambar 7. Halaman Master Data Instansi

c) Master data bantuan

Menu ini untuk mengelola master data program bantuan yang ada. 


\section{KABUPATPN KUTAI KARTANBGADA}

Manajemen Data Bantuan

\begin{tabular}{|c|c|c|c|}
\hline Kode Bantuan & Nama Bantuan & Keterangan & Aksi \\
\hline B003 & ASKESKIN & Asuransi Kesehatan untuk Rakyat Miskin & $\Delta$ \\
\hline B001 & $\begin{array}{l}\text { Beras Untuk Keluarga Miskin } \\
\text { (Raskin) }\end{array}$ & Bantuan Beras Rakyat Miskin dari pemerintah & $\Delta$ \\
\hline B002 & BLT & Program Bantuan Langsung Tunai & $\$ 4$ \\
\hline 8006 & JAMKESDA & $\begin{array}{l}\text { JAMKESDA merupakan program jaminan pelayanan } \\
\text { kesehatan bagi masyarakat miskin dan atau tidak mampu }\end{array}$ & $4 \Delta$ \\
\hline 8005 & Kompor Gas Gratis & kompor gas gratis & 24 \\
\hline B004 & Sekolah Gratis & Sekolah Gratis & $2 \Delta$ \\
\hline B007 & $\begin{array}{l}\text { SWTM - Santunan Warga } \\
\text { Tidak Mampu }\end{array}$ & $\begin{array}{l}\text { Santunan Warga Tidak Mampu (SWTM) merupakan program } \\
\text { santunan yang diberikan oleh Pemerintah Kabupaten kepada } \\
\text { masyarakat Kabupaten Kutai Kartanegara }\end{array}$ & $\Delta \triangle$ \\
\hline
\end{tabular}

Gambar 8. Halaman Master Data Bantuan

d) Master data kriteria

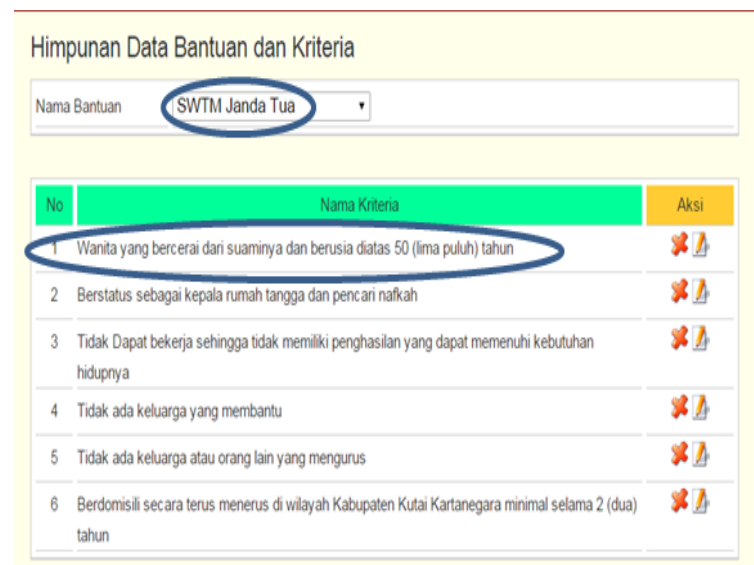

Gambar 9. Halaman Master Data Kriteria

2) Modul himpunan data

Merupakan modul manajemen himpunan data yang telah direlasikan yang berasal dari data master yang terdiri dari:

a) Data kriteria bantuan, adalah proses pemilihan data bantuan dengan data kriteria dalam sebuah relasi.

b) Data himpunan kriteria, adalah hasil relasi data bantuan dengan kriteria yang telah dipilih.

c) Data indikator, adalah proses pembuatan indikator dari kriteria yang telah ditetapkan beserta penentuan nilai pembobotan dari kriteria tersebut.

d) Data himpunan indikator, adalah data hasil proses pembuatan indikator beserta nilai bobotnya.

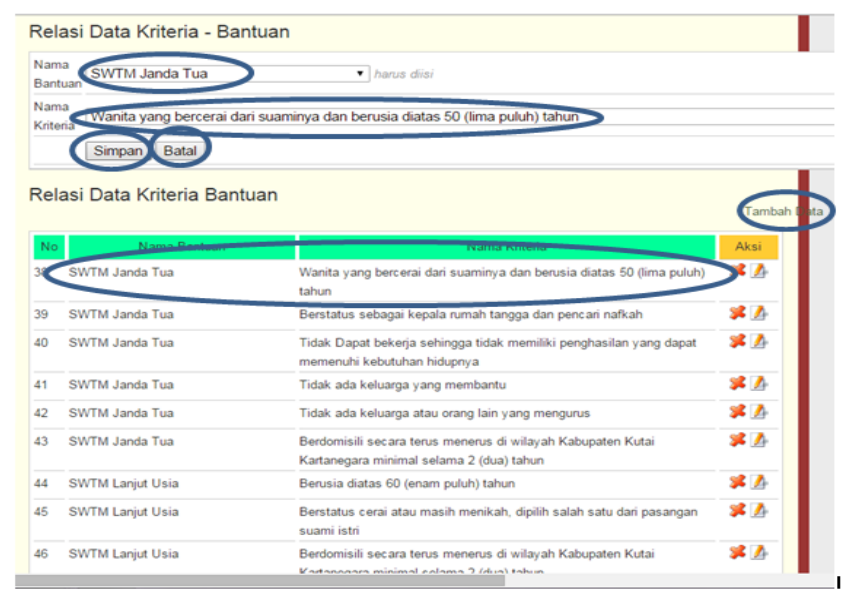

Gambar 10. Menu Himpunan Relasi Data Kriteria dan Data Bantuan 
3) Modul Validasi data

Proses penentuan data warga miskin dilakukan dengan terlebih dahulu memilih warga yang dicalonkan untuk diperiksa bagaimana pemenuhan indikator warga tersebut terhadap kriteria berdasarkan bantuan tertentu. Selanjutnya dilakukan validasi data, untuk memeriksa kondisi real keadaan warga, kemudian hasilnya disimpan untuk kemudian dihitung skor bobot kriterianya dan hasilnya ditampilkan dari skor tertinggi hingga terendah pada laporan penerima bantuan.

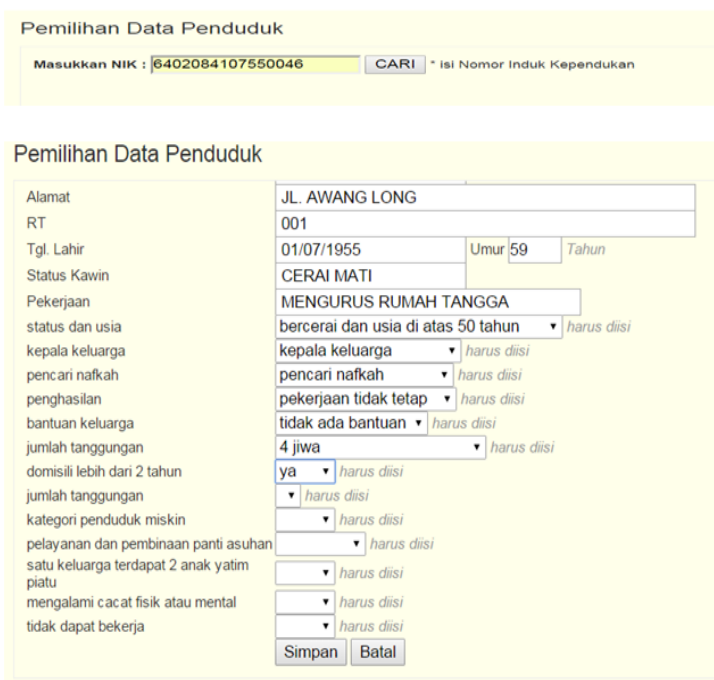

Gambar 11. Input Data Penduduk Calon Penerima Bantuan

4) Laporan penerima bantuan

\section{KABPATEN KUTA KARIAEGA}

Hasil perhitungan Berdasarkan Bobot

\begin{tabular}{ccccc} 
No & Nomor Katu Keluarga & Nama Kepala Keluarga & NLLA & RANKNG \\
\hline 1 & 64020814111076480 & AMAS & 9 & 2 \\
\hline 2 & 64020814111076166 & DURI & 9 & 1 \\
\hline
\end{tabular}

Gambar 12. Laporan Penerima Bantuan

\subsection{Pengujian dan Analisis Hasil Penelitian}

Tabel 1. Hasil Pengujian Blackbox Sistem

\begin{tabular}{llll}
\hline \multirow{2}{*}{ Item Uji } & Pengujian & Hasil Yang Diharapkan & Hasil \\
\hline Form Kriteria & Tambah kriteria & Kriteria tersimpan & Berhasil \\
\cline { 2 - 4 } & Edit kriteria & Kriteria berubah & Berhasil \\
\cline { 2 - 4 } & Hapus kriteria & Kriteria terhapus & Berhasil \\
\hline Form Instansi & Tambah Instansi & Kriteria tersimpan & Berhasil \\
\cline { 2 - 4 } & Edit Instansi & Kriteria berubah & Berhasil \\
\cline { 2 - 4 } & Hapus Instansi & Kriteria terhapus & Berhasil \\
\hline Form & Tambah penduduk & Kriteria tersimpan & Berhasil \\
\hline
\end{tabular}


ILKOM Jurnal Ilmiah Volume 8 Nomor 1 (April 2016)

\begin{tabular}{|c|c|c|c|}
\hline \multirow[t]{2}{*}{ Penduduk } & Edit penduduk & Kriteria berubah & Berhasil \\
\hline & Hapus penduduk & Kriteria terhapus & Berhasil \\
\hline \multirow[t]{3}{*}{ Form Bantuan } & Tambah penduduk & Kriteria tersimpan & Berhasil \\
\hline & Edit penduduk & Kriteria berubah & Berhasil \\
\hline & Hapus penduduk & Kriteria terhapus & Berhasil \\
\hline \multirow{3}{*}{$\begin{array}{l}\text { Form Kriteria } \\
\text { Bantuan }\end{array}$} & Tambah kriteria bantuan & Kriteria tersimpan & Berhasil \\
\hline & Edit kriteria bantuan & Kriteria berubah & Berhasil \\
\hline & Hapus kriteria bantuan & Kriteria terhapus & Berhasil \\
\hline \multirow{3}{*}{$\begin{array}{l}\text { Form } \\
\text { Penerima } \\
\text { Bantuan }\end{array}$} & $\begin{array}{l}\text { Tambah } \\
\text { bantuan }\end{array}$ & Kriteria tersimpan & Berhasil \\
\hline & Edit penerima bantuan & Kriteria berubah & Berhasil \\
\hline & Hapus penerima bantuan & Kriteria terhapus & Berhasil \\
\hline Form Laporan & $\begin{array}{l}\text { Tampilkan dan cetak } \\
\text { laporan }\end{array}$ & $\begin{array}{l}\text { Laporan ditampilkan } \\
\text { dan dapat dicetak }\end{array}$ & Berhasil \\
\hline
\end{tabular}

Untuk menguji analisis hasil penelitian ini dilakukan dengan mensimulasikan dengan menggunakan 4 program bantuan yang berbeda jumlah indikatornya. Keempat program ini menjadi sasaran pengajuan warga miskin yang kemudian hasilnya ditentukan melalui proses validasi pemenuhan indikator berdasarkan kondisi identitas kemiskinan penduduk. Dari hasil pengujian yang dilakukan didapatkan data warga miskin yang berbeda-beda untuk setiap program. Jumlah indikator program bantuan menjadi faktor utama dalam penentuan data penduduk miskin berdasarkan nilai dan ranking sesuai indikator.

\section{Kesimpulan dan saran}

\subsection{Kesimpulan}

1) Semakin banyak kriteria yang diintegrasikan ke dalam sistem manajemen database dan pengambilan keputusan kriteria penduduk miskin Kabupaten Kutai Kertanegara ini maka akan sangat membantu dalam menghasilkan data penduduk miskin yang ideal.

2) Untuk mendapatkan data warga miskin yang ideal atau tepat menjadi target program penanggulangan kemiskinan, pendekatan yang dilakukan adalah membuat suatu program yang indikatornya dipilih secara detail dan akurat sesuai dengan target program tersebut.

\subsection{Saran}

1) Sistem yang dikembangkan akan menjadi suatu sistem yang ideal bila mampu mengintegrasikan semua indikator-indikator yang ada, baik yang bersifat program maupun indikator yang belum diterapkan dalam suatu program.

2) Sistem ini dapat dikembangkan dengan menambahkan metode sistem pendukung keputusan dalam pengambilan keputusan calon penerima bantuan, sehingga menambah keakuratan dalam perhitungan bobot kriteria masing-masing data calon penerima bantuan yang dimasukkan.

\section{Daftar Pustaka}

[1] Aspar, Samsuri. 2008. Program Santunan Warga Tidak Mampu. Kutai Kartanegara Kaltim.

[2] Badan Pusat Statistik (Statistics Indonesia), 2013. Berita Resmi Statistik Badan Pusat Statistik No.34/07/73/Th. III. Kutai Kartanegara.

[3] BKKBN, Departemen Kesehatan. 2009. Pedoman Pelayanan KB dalam Jaminan KesehatanMasyarakat. Jakarta: BKKBN.

[4] Deny, Wiria Nugraha, 2009, Integrasi Data. Univeritas Singaperbangsa Karawang

[5] Dewanta, Awan Setya. 1995. Kemiskinan dan Kesenjangan di Indonesia, Yogyakarta: Aditya Media.

[6] Kamus Besar Bahasa Indonesia, Edisi ke Empat, Balai Pustaka. 